\title{
The relationship between ideal L2 self, achievement attributions and $\mathrm{L} 2$ achievement
}

\author{
Sibel Çağatay a *(D), İsmail Hakkı Erten ${ }^{b}$ \\ a School of Foreign Languages, Middle East Technical University, Ankara, 06800, Turkey \\ ${ }^{b}$ Department of Foreign Language Education, Hacettepe University, Ankara, Turkey
}

\begin{tabular}{l|l|l} 
Received 21 June 2020 & Received in revised form 24 August 2020 & Accepted 22 September 2020
\end{tabular}

\begin{abstract}
APA Citation:
Çağatay, S. \& Erten, İ. H. (2020). The relationship between ideal L2 self, achievement attributions and L2 achievement. Eurasian Journal of Applied Linguistics, 6(3), 337-359.
\end{abstract}

Doi: 10.32601/ejal.834642

\begin{abstract}
This study examines whether learners' (high vs. low) 'ideal L2 self' exerts an effect on causal attributions and which of these causal attributions could predict future L2 achievement. To this end, 1006 EFL students were invited from a state university in Ankara, Turkey. The data were collected with an attribution scale composed of 29 questions and with a questionnaire containing 10 items measuring learners' ideal L2 self. The researchers also collected the students' achievement scores to measure the predictive power of causal attributions. The impact of high and low ideal L2 self on causal attributions was analyzed through MANOVA and the prediction power of these attributions for achievement was measured through regression analysis using SPSS 23. It was found that learners' ideal L2 self (high vs. low) influenced causal attributions, including ability, school system, teacher, family and classroom environment. It was also found that the attribution to effort, luck and ability are the best predictors of future exam scores of learners. These predictors could provide insightful implications for EFL teachers with regard to the actions they can take in order to diagnose motivationally at-risk students and to boost their motivation through effective designs of interventions embedded into the curriculum.
\end{abstract}

(C) 2020 EJAL \& the Authors. Published by Eurasian Journal of Applied Linguistics (EJAL). This is an open-access article distributed under the terms and conditions of the Creative Commons Attribution license (CC BY-NC-ND) (http://creativecommons.org/licenses/by-nc-nd/4.0/).

Keywords: Language motivation; attribution theory; causal attributions, L2 motivational self- system; ideal L2 self, future achievement

\section{Introduction}

Belief systems deeply-rooted in one's past experiences are likely to exert control over one's life. Attribution Theory is one of the prominent theoretical frameworks of belief systems that attempts to find the reasons for displays of a particular performance. Weiner (1972a, 1972b, 1985, 2001, 2018), as the originator of academic achievement attributions, defines attributions as the perceived causes of one's achievement or failure drawing upon past performance. Theoretically, these reported causes are considered to

\footnotetext{
* Corresponding author. Tel.: +0-0312-210-2160

E-mail address: osibel@metu.edu.tr

http://dx.doi.org/ 10.32601/ejal.834642
} 
be projective as well as influential for the direction of future achievement and prospective motivation of learners (Lim, 2007; Taşkıran \& Aydın, 2017; Weiner, 1972b, 1985, 2001, 2010; Williams, Mercer, \& Ryan, 2015). Another influential theory on motivation as well as belief systems is L2 motivational self-system (Dörnyei, 2005; 2009) proposing implications for one's own future image and future success. This theoretical framework is mainly composed of three elements: ideal L2 self, referring to one's own self-image for the future as to a learner's own second language use, ought-to self, meaning the motivational orientations directed by one's own responsibilities, duties and other regulations, and language learning experience concerning every process and stakeholder in language learning (Dörnyei, 2005; 2009). The first component particularly, ideal L2 self, enables a language learner to visualize himself/herself as an effective language learner so that s/he can strive for success more by adhering to the future image (Dörnyei \& Chan, 2013; Dörnyei \& Ushioda, 2011). Both attribution theory, mainly focusing on past experiences, and ideal L2 self, dwelling more on future experiences, theoretically contribute to one's own future motivation as well as one's achievement. However, this potential link has not been investigated in the language learning field. To this end, the present study will mainly focus on the, as yet, unexplored relationship between causal attributions and ideal L2 self to shed light onto the potential link between the motivational patterns of past and future related beliefs. Moreover, there have not been many studies focusing on the predictive power of causal attributions for future achievement in the language learning milieu. In an attempt to reveal this relationship, the present study will investigate language learners' reported causal attributions for their previous exam scores and their accountability for any subsequent exam performance.

In academic encounters, learners tend to present a wide range of reasons for their performance, including but not limited to effort, ability, task difficulty or luck, which are indicated as the main causes of success or failure. To clarify further, if a learner fails in an exam and s/he gives the teacher as the main factor for poor performance, the attribution to the teacher is considered to affect the subsequent motivation of the learner as well as their future effort in a negative manner. In addition to the four main attributions depending on the learning context, students might link their achievement to their classroom environment, school climate, family or strategy use (Graham, 2004; Vispoel \& Austin, 1995; Williams, Burden, Poulet, \& Maun 2004). All the causes that are noted by the learner affect one's own long-term perseverance, motivation, or the amount of effort one puts into prospective performance. Thus, beliefs or causal attributions based on past achievement determine how one takes action on one's own learning path (Hashemi \& Zabihi, 2011; Lim, 2007; Taşkıran \& Aydın, 2017; Weiner, 1972b; 1985; 2001; 2010; Williams et al., 2015).

\subsection{Dimensions of Causal Attributions}

Weiner (1972a, 1972b, 1985, 2010), the pioneer of attribution theory, notes that perceived causes of the occurrence of events are based on three different dimensions. The first, locus of causality, denotes whether the attribution to a specific factor of 
academic performance is perceived within or outside the learner's control. Drawing upon this dimension, effort and strategy, for example, are seen as internal causes that can be changed by learners' actions, thereby becoming more conducive to future success. On the other hand, if a learner fails and blames the teacher or the school system for poor performance, the learner will tend to believe that these outside factors were more influential on the learner's previous experiences, so such a belief is likely to shape prospective achievements negatively.

The second dimension, stability, refers to whether or not perceived reasons for any past performance are liable to change in time. To illustrate, effort is regarded as an internal and unstable causal attribution that is not fixed and can be increased, whereas ability is mostly seen as relatively fixed. The last dimension of the theory, controllability, means the degree of control one perceives to have over past experiences. To illustrate, learners in academic contexts might feel that they have established less control over events when they believe that task difficulty or luck are the main reasons for their previous actions. In such cases, these learners may not adequately strive for success and they become prone to abandon studying.

The most important aspect of this dimensional framework is that, rather than the reason itself, its dimensions shape the conceptualization of how events unfold in the future. That is, the perceived causes of the academic performance of a learner determine how they will act and react in future academic situations. The dimensions of this theory characterize two main types of attributional styles of learners, differentiating them pertaining to their sustained effort and long-term perseverance in their future learning process. If learners fail in a language task, or during their learning process, and tend to refer to their own lack of ability, a stable and internal attribution, these students become likely to hold strong beliefs about themselves as incompetent in language learning, which is categorized as a maladaptive attributional style. However, if such learners think themselves as having employed ineffective or wrong strategies (perhaps categorized as being an unstable, internal and controllable attribution), they will possibly believe in themselves as being more capable of achieving in the future (Weiner, 2014, 2018), thus developing an adaptive attributional style. The most frequent attributions along with their dimensions are presented in Table 1:

Table 1. Relationships among the most widely cited achievement attributions and dimensions

\begin{tabular}{llll}
\hline & $\begin{array}{l}\text { Locus } \\
\text { of control }\end{array}$ & Stability & Controllability \\
\hline Ability & Internal & Stable & Uncontrollable \\
Effort & Internal & Unstable & Controllable \\
Luck & External & Unstable & Uncontrollable \\
Task difficulty & External & Stable & Uncontrollable \\
Strategy & Internal & Unstable & Controllable \\
Interest & Internal & Unstable & Controllable \\
Family & External & Stable & Uncontrollable \\
Teacher & External & Stable & Uncontrollable
\end{tabular}




\begin{tabular}{|c|c|c|c|}
\hline School System & External & Stable & Uncontrollable \\
\hline $\begin{array}{l}\text { Classroom } \\
\text { Environment }\end{array}$ & External & Stable & Uncontrollable \\
\hline Health & External & Unstable & Uncontrollable \\
\hline
\end{tabular}

Adaptive and maladaptive attributional styles have congruent conceptualizations of motivational acts with the fixed and growth mindset theory of Dweck (2006) in terms of malleability of a reason or a trait. To exemplify, as Mercer (2011) underscores, the "language learning mindset reflects the extent to which a person believes that language learning ability is dependent on some immutable, innate talent" (p. 22). Similar to this premise, Dweck (2006) proposed that thinking one is born with a talent such as language aptitude and having no control over it in educational settings, a learner is likely to develop a fixed mindset, hence the possibility of losing hope and motivation for future success in addition to the relinquishment of the completion of tasks. On the other hand, when individuals hold optimistic views about themselves with regard to their potential to learn rather than holding a static ability, such individuals could steer themselves towards being more proactive learners. Therefore, having a more growthoriented mindset may enable such individuals to take control over their learning by employing more effective strategies and putting more effort into their learning.

There exist a wide range of studies on achievement attributions in language learning (Dong, Stupnisky $\quad$ \& Berry, 2013; $\quad$ Erten \& Burden, 2014; $\quad$ Satıcılar, 2006; Taşkıran, 2010; Zohri, 2011), focusing on the link between attributions and gender (Dong, Stupnisky, \& Berry, 2013; Koçyiğit, 2011; Satıcılar, 2006; Taşkıran, 2010; Zohri, 2011), the underlying reasons for some learners tending to ascribe their failure to external causes and generate more positive attitudes and reasons for their successful performances (Gobel \& Mori, 2007; Hashemi \& Zabihi, 2011; Höl, 2016; Koçyiğit, 2011; Mori, Thang, Nor, Suppiah, \& Oon, 2011; Özkardeş, 2011; Şahinkarakaş, 2011; Taşkıran, 2010). The common point in all these studies is the possible future effect of causal attributions on learners' subsequent achievement. Such an implication is derived from the findings of these studies, but most of the studies have performed descriptive statistics. Moreover, inferential analyses of this potential relationship are to be scrutinized as the overall analyses despite descriptive statistics having failed to offer deeper insights into this potential relationship (Erten \& Burden, 2014).

A number of empirical studies have employed more inferential statistics such as regression tests to shed light on which causal attributions for past experiences may account for future achievement. In most of these studies, a general pattern of four causal attributions was found to be responsible for prospective achievement. To illustrate, effort, as a controllable and internal factor, was found as the primary account for future achievement in most studies (McClure, Meyer, Garisch, Fischer, Weir, \&Walkey, 2011); Lei \& Qin, 2009; Pishghadam \& Zabihi, 2011). As for luck, Pishghadam and Zabihi (2011) found that it explains future achievement significantly. Elliot (2005), Erten \& Burden (2014), Hsieh \& Schallert (2008) and McClure et al. (2011) revealed ability to be one of the best predictors of success. 
Regarding the teacher, as the unstable and uncontrollable factor, it is one of the most frequently cited attributions by students in eastern and collectivist cultures (Erten \& Burden, 2014; Gobel \& Mori, 2007). McClure et al. (2011), Paker \& Özkardeş-Döğüş (2017), Williams et al. (2015) and Erten and Burden (2014) found it to be one of the best predictors of future achievement. Conducted in many different contexts, these studies seem to have presented common findings related to similar causal attributions accounting for future success. However, to the knowledge of the researchers, no study has been performed to determine whether achievement attributions were the predictors of future success despite the theoretical framework proposed by Weiner $(1985 ; 2001 ; 2014 ; 2018)$ strongly arguing for this point. This extrapolation could show what attributions could pave the way for more adaptive styles and attainment of language learning goals and long-term achievement.

\subsection{L2 Motivational Self-System}

Belief systems residing in past experiences - in other words, attributions - play a central role in future achievement and the motivational orientation of learners. Similarly, one's own visualization of one's self as L2 users in the future in addition to what extent their current state overlaps with this future self shapes one's own future motivation and subsequent actions (Al-Shehri, 2009; Dörnyei, 2005; Ushioda \& Dörnyei, 2009). In this regard, attribution theory based on past experiences and L2 motivational self-system directing one toward future acts seem to be parallel in affecting one's prospective achievements indirectly.

Dörnyei (2005), the originator of the L2 motivational self-system, identifies three dimensions, each of which has different roots of motivational orientations, highlighting the complexity of one's own current psychological state and its connection to future states or obligations. The first component of the theoretical framework is the ideal L2 self, which refers to the imagined future self different from the current state in relation to how much one uses L2 (Williams et al., 2015). In other words, it encompasses one's own aspirations, hopes and goals specifically using their L2 during their future L2 encounters. To exemplify, a young researcher can envision himself/herself as an effective and competent presenter at a very influential conference in the field (Williams et al. 2015). Another example might be the imagination of a language user speaking fluent English at an international company in the future. As Williams et al. (2015) proposed, the ability to envision enables people to experience events in their imagination and to visualize the self-representations in their future state. The important point is one's competency in lowering the discrepancy between a current actual self or state and the imagined self or ideal L2 self (Dörnyei, 2005). To maximize the effects of the ideal L2 self, it needs to meet a number of criteria. To illustrate, a learner has to have a desired future self image; the future self has to be quite different from one's current self; and it needs to be vivid, elaborate or plausible (Magid, 2011). 
Scholars hold different views on the conceptualization of the ideal L2 self. That is, some consider learners as internally motivated as they (learners) can personalize their dreams or imagined themselves as they wish. However, Munezane (2015) regards the term as related to instrumental motivation. To clarify, one wishes to travel internationally and uses English effectively in his/her imagination; however, this image might result from instrumental reasons such as the desire to travel rather than using English in real life. Given this unclear line between its being internal or external, its internal or external roots have not been explored in any research.

The second aspect of the L2 motivational self system is known as ought-to self, which is the motivational orientation deriving from one's own obligations, responsibilities or duties (Dörnyei, 2005, 2009). To illustrate, one may want to learn English as his/her family wants him/her to learn it or s/he has to learn English as the school offers English as the medium of instruction. All these outside factors present a number of obstacles for the learner, pushing the learners to learn the L2.

The final facet of the theory is called L2 learning experience, which refers to "the situation specific motives related to the immediate learning environment and experience" (Dörnyei, 2009, p. 29). Munezane (2015) and Dörnyei (2019) exemplify it by giving a reference to the pleasing or positive feeling learners experience during a language class, which might be quite context-specific. This aspect might be closely interwoven with school or classroom climate, peer or group members or curriculum (Csizér \& Dörnyei, 2005).

As future self-guides, the ideal L2 self is especially a relatively new term. There is an increasing number of empirical studies throwing light onto the potential relationship between it and emotional output (Teimouri, 2017), self-efficacy (Roshandel \& Ghonsooly, Ghanizadeh, 2018) and willingness to communicate (Öz, 2015), how it affects learning and learning behaviors (Brady, 2019; Wen \& Piao, 2020). However, to the knowledge of the researchers, potential reciprocal interaction or causal paths between the ideal L2 self and attributions have not yet been explored. This deeper exploration may generate valuable information on construing the causal relationship between the past and present motivational continuum by addressing both attribution-based motivation and future self-guides.

Another point that was seldom handled was whether past-rooted attributions could predict any future performance of language learners. Although such studies as Erten and Burden (2014), Hsieh and Schallert (2008), and Hsieh and Kang (2010) investigated in detail which attributions could explain the previous achievement of learners, few studies (Hashemi \& Zabihi, 2011) focused on whether causal attributions may account for the future performance of learners. Some attempted to reveal which causal attributions may explain the previous performance of learners (Erten \& Burden, 2014; Hsieh \& Schallert, 2008; Hsieh \& Kang, 2010). However, very few studies (Hashemi \& Zabihi, 2011; McClure et al., 2011; Lei \& Qin, 2009) have shed light on whether academic attributions could account for future performance in language learning, each of which has a number of methodological or theoretical 
repercussions. Hashemi and Zabihi (2011) and McClure et al. (2011) did not employ a psychometrically-validated and a reliable attribution scale and they included participants ranging from different age groups; however, age differences matter in attribution studies (Erten, 2015) in order to draw solid conclusions, so not having homogenous groups in terms of age may not yield reliable findings. Lei \& Qin (2009) administered their scale to relatively few participants to make generalizations in a regression test (Pallant, 2011). More importantly, only one study in the language learning field may be insufficient for the establishment of a theory, indicating the need for a close examination of this gap in language learning contexts as Weiner $(1972 b ; 1985 ; 2001)$ theoretically posits that academic attributions are regarded as indicators of subsequent achievements.

\subsection{Significance and Aim of the Study}

Considering these gaps in the field, the study is concerned with gaining insight into the relationship between the attributions of EFL learners at the tertiary level and their ideal L2 self. It further focuses on the link between students' attributions and their future exam performance.

\subsection{Research Questions}

The following research questions will be addressed in the present study:

1. Do students' high and low ideal L2 selves differ on their causal attributions for the latest exam scores? If so, which attributions make a difference?

2. Is it possible to predict students' future achievement by means of their attributions for any past exam performance? If so, what are the best predictors?

\section{Method}

\subsection{Setting and Participants}

In the fall term of the 2016-2017 academic year, data were collected from 1,006 students enrolled in the preparatory program of a state university in Turkey. The students were placed in five different groups in this department at the beginning of the year and provided with a one-year intensive program focusing on both general and academic English to enable them to follow their courses in the medium of instruction of English during their undergraduate program. During this preparatory year, students were placed into $\mathrm{A} 1, \mathrm{~A} 1+, \mathrm{A} 2, \mathrm{~A} 2+$ and $\mathrm{B} 1$ levels receiving different contact hours of instruction in accordance with their level. As for the present study, 1,006 students from students at the A1, A1+ and A2 levels were recruited as participants. The rationale and underlying reason for employing data collection procedures with these groups is that it was more possible to identify unsuccessful and motivationally-at-risk students at the lowest proficiency level. As the literature suggests (Groves, 2014; Haynes, Perry, Stupnisky, \& Daniels, 2009; Perry, Stupnisky, Hall, Chipperfield, \& Weiner, 2010), disadvantaged students such as lower level students pertaining to their language 
competencies yielded more enriched data for researchers. Another reason to choose first-year university students is that, as Haynes et al. (2009) suggest, attribution studies are suitable for the participants going through a change in their lives. In academic contexts, freshmen may experience a number of adaptation problems as they start to live independently from their parents for the first time. The reason for the selection of lower level students was that the majority of participants fell into the lower levels considering their rate, which approximately equals 2,000 students out of 3,200 in this school context. In the questionnaire, some demographic questions concerning gender, department, duration learning English, primary school and high school types were addressed to the participants.

\subsection{Instruments}

The present study dwells basically on pure quantitative data collected through exam scores measuring success/achievement and the language attribution scale (LACAS) to measure causal attributions and ideal L2 self scale. The details of the scales are given below.

\subsubsection{Success/Achievement}

The construct of success in the present study was measured through the first achievement exam, i.e., the first midterm, of the semester. The midterm grades for the present research were received from the computer center of the department. The exam papers were marked by the class instructors, but the open-ended questions, such as the writing tasks and some reading comprehension questions were checked by two instructors to ensure inter-rater reliability. In the present study, while causal attributions for the first midterm exam performances, considered as the indicator of past achievement, were used, the second midterm scores were taken as data referring to future achievement.

In this school context, midterm exams are administered three times per semester, aiming to measure whether the syllabus objectives for reading, listening and writing skills as well as language competency in vocabulary and grammar are have been by the students. Some reading and writing questions are prepared in an open-ended format, but some of the reading and listening skills, grammar and vocabulary questions are directed to students in either a multiple-choice format or a gap-filling format. Speaking skills are tested indirectly in questions where students are expected to complete missing parts in a dialogue or they are asked to respond to a given situation. In fact, speaking proficiency is measured directly in face-to-face speaking tests.

\subsubsection{Language Achievement Causal Attribution Scale (LACAS)}

The Language Achievement Causal Attribution Scale (LACAS), developed by researchers Erten \& Çağatay (2020), aims to measure language learners' attributions for specific exams or task performances. It incorporates nine sub-categories: ability, 
effort, luck, task difficulty, family, teacher, school system, classroom environment and health, with 29 questions. To ensure validity and reliability, a pilot study was conducted on a different group of participants during the 2015-2016 academic year with the initial draft of the scale being administered to 657 students at the A2 level. Validity and reliability details of the pilot study and its findings are presented in Çağatay and Erten (2020). Confirmatory factor analysis (CFA) was performed using structural equation modeling (SEM) in IBM Analysis of Moment Structures (AMOS) version 23 to explore the interconnected relationships in one model. The CFI and GFI were found to be .94 and .92, respectively, and the RMSEA was revealed to be .049 , which indicated a good fit of the model (Erkorkmaz, Etikan, Demir, Özdamar \& Sanisoğlu, 2013; Hu \& Bentler, 1999; Kline, 2011; Tabachnick \& Fidell, 2013). The details of the validity and reliability of the scale were presented and discussed in detail in Erten \& Çă̆atay (2020).

In an attempt to measure learners' ideal selves, the translated and validated version (Ayaz-Demir, 2016) of the Future Self-Guides scale (Taguchi, Magid, \& Papi, 2009) was administered to 1,006 students from A1, A1+ and A2 levels with an initial data screening. The scale of the ideal L2 self, as an indicator of vision, incorporates ten items. The validity and reliability of each scale was tested and presented in the pilot study (Çağatay \& Erten, 2020). As for the main study, the reliability scores found for CDS II were as follows: locus of causality, $r=0.69$; stability, $r=0.77$; personal control, $r=.74$; external control, $r=.63$. The reliability for the LACAS was effort, $r=0.90$; ability, $r=0.87$; teacher, $r=0.80 ;$ health, $r=.83$; school system, $r=0.79 ;$ family, $r=0.76$; task difficulty, $r=0.78$; classroom environment, $r=0.76$; luck, $r=0.72$. The internal consistency for the ideal L2 self scale was also found to be highly reliable with a score of .90 .

\subsection{Procedures for Data Collection and Analysis}

Initially, consent forms were sent to the students and then the attribution scales, LACAS and ideal L2 self scales, were given to 1,006 students, including 308 at the A1, 451 at $\mathrm{A} 1+$ and 239 students at the A2 levels after the first midterm results were announced. The scales were sent to the researchers' colleagues and the return rate of the data collection on the scales was $80 \%$.

The data analysis was performed on SPSS 23, and descriptive statistics were used for both research questions. As for the first research question, specifically, the Pearson Correlation Coefficient and a MANOVA analysis were performed to determine whether the students with high ideal L2 self scores and low ideal L2 self scores varied in correlation to their causal attributions. Groupings of ideal L2 self were taken as independent variables while achievement attributions for the first midterm, as the previous exam scores, were treated as a dependent variable. For the second research question, a stepwise regression analysis was employed to reveal whether causal attributions for the previous exam (midterm 1) could predict learners' future exam achievements through the second midterm. As Pallant (2011) and 
Tabachnick \& Fidell (2013) point out, 8 participants for each independent variable yielded more robust results, so the number of participants (low ideal $N=353$; high ideal $N=582$ ) was sufficient for the analyses.

\section{Results}

In order to explore whether the ideal L2 self varies across causal attributions, students would initially be grouped as participants with a high ideal L2 self and those with a low ideal L2 self. This distinction was not prescriptive as to whether participants needed to be classified as learners with high or low scores, but to make it more standardized, clustering was used. In fact, a K-means cluster analysis procedure using SPSS 23 was followed to differentiate between these two groups on a standardized basis, allowing the researchers to have relatively homogeneous groups of participants within pre-determined variables so that group differences could be identified easily. Depending on the participants' ideal L2 self scores, the first group had a lower mean score $(N=367, M=2.97)$ than the second cluster $(N=612, M=4.22)$; hence, they are taken as students with 'high ideal L2 self' and 'low ideal L2 self', meaning those with clear vision and blurry vision, respectively, $(F=1793.685, p .000)$. These classifications will be considered as the basis of comparisons in the subsequent analysis.

\subsection{The difference between high and low ideal L2 self across causal attributions}

A one-way MANOVA was conducted to scrutinize the potential impact of the ideal L2 self on the attributions. The findings reveal a major effect on the causal attributions at a statistically significant level $(\Lambda=.929, F=7.883, p=.000)$, indicating a moderate effect size (partial $\eta^{2}=.71$ )

As indicated in the table below, with the exception of health, students with a high level of ideal L2 self seem to endorse more positive attributions for their exam scores low ideal L2 self $=4.30$; high ideal L2 self $=4.28 ; F=0.83 ; p=.77 ; \eta^{2}=.000$ ). Both groups appear to display a similar order of attributions. In comparison to the participants achieving low ideal L2 self scores, those with high mean scores tended to hold more positive views on ability (low ideal L2 self $=3.07$; high ideal L2 self $=3.57$; $F=62.240 ; p=.000 ; \eta^{2}=.063$ ), school system (low ideal L2 self $=3.75 ;$ high ideal L2 self $=3.94 ; F=16.557 ; p=.000 ; \eta^{2}=.017$ ), teacher (low ideal L2 self $=4.21$; high ideal L2 self $\left.=4.35 ; F=10.393 ; p=.001 ; \eta^{2}=.011\right)$, family $($ low ideal L2 self $=3.52$; high $i d e a l$ L2 self $=3.68 ; F=4.561 ; p=.033 ; \eta^{2}=.005$ ) and classroom environment (low ideal L2 self $=4.05$; high ideal L2 self $\left.=4.16 ; F=3943 ; p=.047 ; \eta^{2}=.004\right)$.

Table 2. Achievement attributions according to ideal L2 self

\begin{tabular}{lllllll}
\hline & \multicolumn{2}{l}{ Low Ideal L2 Self } & & \multicolumn{2}{l}{ High Ideal L2 self } \\
\hline \multirow{2}{*}{ Health } & $\mathrm{N}$ & Mean & SD & N & Mean & SD \\
Teacher & 353 & 4.30 & 0.80 & 582 & 4.28 & 0.92 \\
Classroom Environment & 353 & 4.21 & 0.63 & 582 & 4.35 & 0.64 \\
& 353 & 4.05 & 0.82 & 582 & 4.16 & 0.84
\end{tabular}




\begin{tabular}{lllllll} 
Luck & 353 & 3.89 & 0.95 & 582 & 3.93 & 1.05 \\
School System & 353 & 3.75 & 0.69 & 582 & 3.94 & 0.72 \\
Task Difficulty & 353 & 3.66 & 0.71 & 582 & 3.72 & 0.74 \\
Family & 353 & 3.52 & 1.03 & 582 & 3.68 & 1.08 \\
Ability & 353 & 3.07 & 0.83 & 582 & 3.51 & 0.83 \\
Effort & 353 & 2.85 & 0.98 & 582 & 2.93 & 1.05 \\
\hline
\end{tabular}

Such attributions as health (low ideal L2 self $=4.30$; high ideal L2 self $=4.28$; $F=.083 ; p=.773$ ), effort (low ideal L2 self $=2.85$; high ideal L2 self $=2.93 ; F=1.350$; $p=.246$ ); task difficulty (low ideal L2 self $=3.66$; high ideal L2 self $=3.72 ; F=1783$; $p=.182$ ) and luck (low ideal L2 self $=4.05$; high ideal L2 self $=4.16 ; F=282 ; p=.596$ ) did not reveal a statistically significant difference. Further details of the mean differences are presented in Table 3 below:

Table 3. Comparisons of means according to ideal L2 self of participants' causal attributions

\begin{tabular}{|c|c|c|c|c|c|}
\hline Dependent Variable & (I) Ideal L2 Self & (J) Ideal L2 Self & $\begin{array}{l}\text { Mean } \\
\text { Difference (I-J) }\end{array}$ & Std. Error & Sig. $^{b}$ \\
\hline \multirow[t]{2}{*}{ Effort } & Low Ideal L2 self & High Ideal L2 self & -.080 & .069 & .246 \\
\hline & High Ideal L2 self & Low Ideal L2 self & .080 & .069 & .246 \\
\hline \multirow[t]{2}{*}{ Health } & Low Ideal L2 self & High Ideal L2 self & .017 & .059 & .773 \\
\hline & High Ideal L2 self & Low Ideal L2 self & -.017 & .059 & .773 \\
\hline \multirow[t]{2}{*}{ Ability } & Low Ideal L2 self & High Ideal L2 self & $-.442^{*}$ & .056 & .000 \\
\hline & High Ideal L2 self & Low Ideal L2 self & $.442^{*}$ & .056 & .000 \\
\hline \multirow[t]{2}{*}{ School System } & Low Ideal L2 self & High Ideal L2 self & $-.196^{*}$ & .048 & .000 \\
\hline & High Ideal L2 self & Low Ideal L2 self & $.196^{*}$ & .048 & .000 \\
\hline \multirow[t]{2}{*}{ Teacher } & Low Ideal L2 self & High Ideal L2 self & $-.139^{*}$ & .043 & .001 \\
\hline & High Ideal L2 self & Low Ideal L2 self & $.139^{*}$ & .043 & .001 \\
\hline \multirow[t]{2}{*}{ Task Difficulty } & Low Ideal L2 self & High Ideal L2 self & -.066 & .049 & .182 \\
\hline & High Ideal L2 self & Low Ideal L2 self & .066 & .049 & .182 \\
\hline \multirow[t]{2}{*}{ Family } & Low Ideal L2 self & High Ideal L2 self & $-.154^{*}$ & .072 & .033 \\
\hline & High Ideal L2 self & Low Ideal L2 self & $.154^{*}$ & .072 & .033 \\
\hline \multirow[t]{2}{*}{ Luck } & Low Ideal L2 self & High Ideal L2 self & -.036 & .069 & .596 \\
\hline & High Ideal L2 self & Low Ideal L2 self & .036 & .069 & .596 \\
\hline \multirow{2}{*}{$\begin{array}{l}\text { Classroom } \\
\text { Environment }\end{array}$} & Low Ideal L2 self & High Ideal L2 self & $-.113^{*}$ & .057 & .047 \\
\hline & High Ideal L2 self & Low Ideal L2 self & $.113^{*}$ & .057 & .047 \\
\hline
\end{tabular}

Note: a. Based on estimated marginal means

* The mean difference is significant at the 0.05 level.

b. Adjustment for multiple comparisons: Bonferroni.

\subsection{Achievement Attributions and Exam Scores}

Research Question 2 aims to reveal a possible causal link between learners' perceived causes of their previous exam performance (Midterm 1) and their future exam score 
(Midterm 2), which was computed on SPSS 23 with the Pearson Product-Moment Correlation. Based on this analysis, the predictive power of nine causal attributions was examined through stepwise regression analysis.

\subsubsection{The relationship between future exam scores and causal attributions}

In order to test whether beliefs about the past, measured by perceived attributions in the present study, could predict the prospective achievement of learners, stepwise regression analysis on SPSS was conducted. Before the inferential analysis, the Pearson product-moment correlation was implemented to examine the link between nine causal attributions and their future exam scores as suggested by Pallant (2011). The details of the results are presented below.

Table 4. Pearson product-moment correlations between attributions and future exam scores

\begin{tabular}{|c|c|c|c|c|c|c|c|c|c|c|c|c|c|}
\hline \multicolumn{14}{|l|}{ Correlations } \\
\hline & 1 & 2 & 3 & 4 & 5 & 6 & 7 & 8 & 9 & 10 & 11 & 12 & 13 \\
\hline 1.Midterm 2 & 1 & & & & & & & & & & & & \\
\hline 2.Effort & $.236^{* *}$ & 1 & & & & & & & & & & & \\
\hline 3.Health & $.122^{* *}$ & .015 & 1 & & & & & & & & & & \\
\hline 4.Ability & $.141^{* *}$ & $.178^{* *}$ & .055 & 1 & & & & & & & & & \\
\hline 5.School System & .070 & $.171^{* *}$ & $.209^{* *}$ & $.256^{* *}$ & 1 & & & & & & & & \\
\hline 6.Teacher & $.112^{* *}$ & $.103^{* *}$ & $.222^{* *}$ & $.222^{* *}$ & $.479^{* *}$ & 1 & & & & & & & \\
\hline 7.Task Difficulty & $.118^{* *}$ & .060 & $.446^{* *}$ & $.087^{* *}$ & $.290^{* *}$ & $.185^{* *}$ & 1 & & & & & & \\
\hline 8.Family & .009 & $.172^{* *}$ & .019 & $.212^{* *}$ & $.243^{* *}$ & $.231^{* *}$ & .055 & 1 & & & & & \\
\hline 9.Luck & $.148^{* *}$ & .008 & $.455^{* *}$ & $.123^{* *}$ & $.261^{* *}$ & $.284^{* *}$ & $.424^{* *}$ & .027 & 1 & & & & \\
\hline $\begin{array}{l}\text { 10.Classroom } \\
\text { Environment }\end{array}$ & .064 & $.094^{* *}$ & $.261^{* *}$ & $.157^{\text {** }}$ & $.451^{* *}$ & $.423^{* *}$ & $.276^{* *}$ & $.160^{* *}$ & $.225^{* *}$ & 1 & & & \\
\hline
\end{tabular}

Note. ${ }^{* *}$ Correlation is significant at the 0.01 level (2-tailed)

*Correlation is significant at the 0.05 level (2-tailed)

As illustrated in the table above, the majority of the variables appear to be positively correlated at a statistically significant level. Pertaining to future exam scores and other variables being explored, future exam performance appears to be correlated with all but school system, family, and classroom environment.

As presented in Table 4, effort $(r=0.236, p<0.01)$, health $(r=0.122, p<0.01)$, ability $(r=.141, p<.01)$, teacher $(r=.112, p<0.01)$, task difficulty $(r=.118, p<.01)$, and luck $(r=.148, p<.01)$ were found to be interwoven with future exams at a statistically significant rate.

\subsubsection{Predictive Power of Attributions for Future Achievement}

In the correlation analysis, six attributions were explored in relation to their predictability of the students' future success - operationalized through the next midterm scores. The stepwise regression analysis was used to test the theoretically proposed argument in the present study (Lim, 2007; Weiner, 1986, 2010). 
Pallant (2011) suggests that sample size is an important criterion to perform regression analysis. Considering the suggested formula $(N>50+8 \mathrm{~m})$ proposed by Tabachnick and Fidell (2013), the sample size of the present study falls into the satisfactory level for a regression analysis $(N=652)$.

Preliminary analyses for the regression analysis were employed to ensure "no violation of the assumptions of normality, linearity, multicollinearity and homoscedasticity" (Pallant, 2011, p. 149). In order to explore to what extent the six factors account for the variance, a stepwise regression was performed, entering the variables effort, health, ability, teacher, task difficulty and luck as independent variables and Midterm 2 scores as an indication of prospective achievement as the dependent variable. The findings are summarized in the table below:

Table 5. Stepwise multiple regression analyses of future exams $(N=652)$

\begin{tabular}{llllllll}
\hline \multicolumn{5}{c}{$\begin{array}{l}\text { Standardized } \\
\text { Coefficients }\end{array}$} & & \multicolumn{3}{c}{ Correlations } \\
Predictors & $B$ & $\mathrm{t}$ & Sig. & Zero-order & Partial & Part \\
\hline 1 & Effort & .235 & 6.077 & .000 & .235 & .235 & .235 \\
& Effort & .235 & 6.117 & .000 & .235 & .237 & .235 \\
& Luck & .128 & 3.328 & .001 & .128 & .132 & .128 \\
& Effort & .219 & 5.614 & .000 & .235 & .219 & .215 \\
3 & Luck & .117 & 3.032 & .003 & .128 & .120 & .116 \\
& Ability & .086 & 2.193 & .029 & .142 & .087 & .084 \\
\hline
\end{tabular}

Note. Adjusted R2 for Model 1=0.054; Model 2=0.069; Model $3=0.074$

Learners' perceiving credit to effort, luck, and ability was found to be a strong predictor of future achievement, explaining $7.9 \%$ of the total variation $\left(R^{2}=.079\right.$; Adjusted $R^{2}=.074$ ).

In the first step, effort entered the equation, accounting for a unique $5.5 \%$ of the total variation $\left(R^{2}=.055, F\right.$ change $\left.=36.924, p=.000\right)$. Luck was involved in the regression model as a second phase to explain $7.2 \%$ of the total variation $\left(R^{2}=.072\right.$, $F$ change $=11.075, p=.003)$. In the final phase, ability increased the total variation to $7.9 \%$ with a unique variation of $0.7\left(R^{2}=.079, F\right.$ change $\left.=8.172, p=.029\right)$.

\section{Discussion}

\subsection{Discussion of research Question 1: The difference between high and low ideal L2 self across causal attributions}

In line with the process-oriented theories of motivation (Williams et al., 2015), an individual's past-oriented actions and motivational orientations play a crucial role in their future motivation and actions. In this vein, the present study aims to disclose whether EFL learners' ideal L2 self referring to their future selves varies across attributions they have made for their past learning experiences or exam performance. The finding relating to whether participants' ideal L2 self level made a difference to 
their achievement attributions in the first research question indicated that learners with high levels of ideal L2 self scores have a tendency to hold more promising and adaptive attributional styles, resonating with the theoretical background of the ideal L2 self in that participants conforming to such a profile are likely to adopt more positive attitudes (Dörnyei, 2005). Those who have clearer ideal L2 selves seem to have more positive causal attributions, including teacher, effort, ability, task difficulty, health, luck and classroom environment. The findings of the first research question will be discussed in alignment with the specific causal attributions below:

\subsubsection{Teacher}

The present study revealed that students giving more credence to their future images attach importance to all causal attributions regardless of their adaptability. To exemplify, students with a clear future self guide, or ideal L2 self, endorsed teacher as an influential factor in their previous performance. On a theoretical basis, presumably, learners having a clear as well as vivid ideal L2 self tend to have more control and feel internally more motivated (Kim, 2009) in their own learning as well as attributing this to more internal factors such as effort or employment of effective strategies. However, belief in such attributions as teacher, an external and uncontrollable attribution, is an indication of maladaptive attributional style. In the present study, learners with high scores of ideal L2 self attribute their performance to the teacher, which contrasts the internal nature of having a clear ideal L2 self. That is, learners who cling on uncontrollable reasons, such as teacher, might be inclined to abandon improving their language skills in the future (Erler \& Macaro, 2011). In fact, those developing a clear vision are expected to hold more onto controllable and unstable reasons. At this point, dependence on the teacher on the part of the learners feeling more control and having a clearer ideal L2 self might be explained with reference to the learners' culture. In eastern cultures, learners tend to attribute their academic achievement to their teacher with value and respect for authority, whereas in Western cultures, this is less likely to be so (Erten \& Burden, 2014; Gobel \& Mori, 2007; Horwitz, 1999; Paker-ÖzkardeşDöğüs, 2017). Hence, the dependence on the teacher attribution even for those having high ideal L2 self scores might be an unexpected finding as holding a clear ideal self is expected to have more control. However, Turkish culture seems to allow more space to authority for internally future-oriented students.

\subsubsection{Effort}

Another thought-provoking finding is the low discrepancy between students with high and low ideal L2 self scores in terms of their reference to their expended effort. Theoretically, learners who have clear visions or high ideal L2 self scores are expected to expend more effort as they believe that the learning process is under their control to realize their future image. (Al-Shehri, 2009; Chan, 2014; Dörnyei, 2005; 2009; Papi, 2010; Taguchi et al., 2009). A clearer ideal L2 self enables learners to become engaged in language learning, sustaining their effort and perseverance 
(Al-Shehri, 2009; Chan, 2014; Papi, 2010; Taguchi et al., 2009). In contrast to this argument, participants in this study did not report having expended more effort than the group who scored low on the ideal L2 self scale. Although a difference between these two groups can be observed, it is not at a statistically significant level (see Table 3, $p=.246$ ). This finding might suggest that learners' future selves and effort at a tertiary level are intertwined and it is more complicated to identify the underlying reason for their lack of effort compared to students in elementary education (Dörnyei, Henry \& MacIntyre, 2015 ; Kim \& Kim, 2014). Despite high levels of awareness on the part of university students (Haynes et al., 2009), it is interesting that participants do not seem to expend sufficient effort on the process. This finding might result from the late puberty effect of learners as Erten (2015), which may be attributable to their difficulty in adapting to the responsibilities of academic life in higher education. As the originator of the L2 motivational self-system, Dörnyei (2005; 2009) and Dörnyei et al. (2015) point out that the nature of motivation is not only dynamic but also complex; therefore, it is difficult to identify the actual influential factors.

\subsubsection{Ability}

With regard to the other attributions being explored, ability - an internal and uncontrollable but stable ascription - varied between the participants with high ideal L2 self group and those with lower L2 selves. Such a finding might consolidate the supposedly strong link between self and the internal causes, meaning the ideal L2 self and attribution in this case (Faber, 2017; Weiner, 2014). This internal aspect of both constructs might have caused this difference between the high and low ideal L2 self groups across the ability attribution. On the other hand, in future encounters, the stability and uncontrollability dimensions of ability could pose a challenge when attempting to attain goals or realize dreams on the part of language learners as they believe that they cannot change their current or future selves.

The findings also showed that students with a high ideal L2 self score appear to make references to the school system, teacher and classroom environment for their previous achievement. Such a result is dissimilar to what Dörnyei (2009) proposed with regard to learners' perceived control over their own learning process when they would envision themselves clearly for their future. This contrast between the finding of this study and the conceptual framework of the theories might result from the discrepancy in the authenticity of the exams. That is, learners' clearer ideal L2 selves in relation to their use of English might not overlap with what the standard test aimed to measure, suggesting more authentic and prospective ways of assessment in language learning. To clarify, imagining oneself as an effective speaker of English may not be in line with the objectives or specifications of an achievement test. In such a manner, learners could become more engaged and feel more control over the process by expending more effort to minimize the gap between their actual and ideal selves. 


\subsubsection{Health, Luck, and Task Difficulty}

With the exception of the attributions of health, luck and task difficulty, the other attributions all signal for a high level of engagement and motivation of learners for their future experiences. Their beliefs regarding other attributions stemming from their past performances project their dreams, aspirations and expectations for subsequent acts. The lower difference between the groups in relation to these attributions might be attributable to a number of various factors. For example, as health might be a temporary drawback for a specific exam, it might not be so influential in future performances.

\subsubsection{Task difficulty}

Yet another lower discrepancy between the low and high ideal L2 self groups falls onto task difficulty, implying those with high ideal L2 self depend on an external, stable and uncontrollable reason more compared to the correspondent group, although not at a statistically significant level. This minimal group difference might result from the high mean scores in the first midterm (mean $=76.87 / 100)$ as higher and lower achievers did not differ much as it was the first achievement exam assessing the first two-month syllabus objectives, placing fewer responsibilities on students in terms of workload.

\subsection{Discussion of Research Question 2: Predictive power of attributions for future achievement}

The second research question is concerned with the extent to which causal attributions make to previous exams as well as the ability of learners' ideal L2 self to predict learners' future exam achievements. The regression analysis revealed a small predictive power of attributions for their next achievement exam despite there having been statistically significant differences on effort, luck and ability, each of which will be discussed in the following section.

\subsubsection{Effort}

The regression analysis suggests that perceiving themselves as having expended greater effort in the previous performances, students are likely to achieve more in prospective exams. This finding consistent with what the pioneer of the attribution theory points out (Weiner, 1985; 2001). That is, effort, as a controllable, unstable and internal attribution, could bring about positive effects on subsequent actions of learners with an adaptive attributional style. It is also congruent with the theory of growth mindset (Dweck, 2006), which suggests that individuals fitting into this mindset profile could maintain their long-term effort and their persistence for a longer time. Yet another finding in this study is that when learners are of the opinion that they have the required language ability, they tend to succeed more in the future. This result is in line with Elliot (2005), Hashemi and Zabihi (2011), McClure et al. (2011) and Lei and Qin (2009) as effort is the best predictor of student achievement. This is also consistent 
with Hsieh and Kang 2010 as effort was found to be the other predictor of future achievement.

\subsubsection{Luck}

In the present study, luck, an uncontrollable but stable and external cause (Weiner, 1992) of the performance, added up to the total variance as another factor with a unique variance of $1.63 \%$. The small contribution of luck to the total variance might signal a low relationship between learners' belief in luck and their subsequent achievement, which is quite understandable in that relating one's performance to an external, uncontrollable and unstable reason might not account for a specific achievement in an exam. That is, a learner would believe that $\mathrm{s} / \mathrm{he}$ received a particular score in the first achievement exam because it was 'not his/her lucky day' or 's/he cursed that day.' So-called 'tough luck' on the first exam date does not necessarily affect long term or future exam performance, the second midterm in this case. Therefore, the existence of luck in the proposed model is possible in this statistical analysis, although at a low rate. This might be caused by the fact that luck is reported as one of the most frequently cited attributions in addition to effort, task difficulty and ability (Weiner, 1972a; 1985; 2018). However, it does not appear to be influential in specific future exam conditions.

\subsubsection{Ability}

The present study found a unique contribution of ability to future success, though not to a great extent. This might be due to three factors. One reason could be the cultural effect. Too much reference to the ability attribution is widely seen in individualistic cultures such as Western societies as this attribution does not have much social aspect. The low relationship between ability and future success might be linked to the collectivist culture (Hashemi \& Zabihi, 2011) of Turkish society, in which success is considered to be intertwined with people around the learner, such as attribution to the teacher or classroom climate. Another reason for this finding might be that the ability attribution is strongly linked with overall language learning processes rather than specific exams, which may explain its appearing to be influential in a subsequent achievement, but not to a high degree. The uncontrollable but stable and internal attribution of ability is considered to pave the way for learned helplessness (Seligman, 1975) and causes learners to refrain from taking action. Giving credence to ability might imply a fixed mindset (Dweck, 2006) and learners perceive the learning process as an uncontrollable situation. In this model of the present study, ability might hinder learners from holding their responsibility as learners as they believe their lack of language ability might become a setback for their success. However, the contribution of effort to the model indicates an individual with an adaptive and more promising learner profile and who takes more control and more action in the future. Henceforth, minor contributions of ability along with a major effect of effort attribution might imply future success. 


\subsection{Limitations of the Study}

Despite the first-time exploration of the relationship between ideal self and causal attributions in addition to the low number of studies on the predictive power of attributions for future achievement, this research also has certain limitations. One main limitation is the lack of a longitudinal research design in which belief systems and the process of motivational roots can be best traced. These constructs with regard to belief systems are dynamic as well as complex (Kalaja, Barcelos \& Aro, 2018; Mercer, 2011; Oxford, 2017) and collecting data in the long term could have been better. Another limitation is the data are constrained with a case of a state university. Different profiles in EFL contexts, such as primary or secondary school, might have yielded different results. Still another missing point is the lack of qualitative data to address the research questions. As these findings are preliminary for the first-time examination of the link between the constructs under exploration, further research taking into account these lacking points could provide more insightful implications. The direction of the relationship could also be explored in depth in future studies.

\section{Conclusions}

The study attempted to shed light on the potential relationship between the ideal L2 self as the operational form of images for prospective experiences and the perceived causes of past experiences and attributions. The difference in ability, school system, teacher, family, and classroom environment suggests that learners' own control over their future images makes a difference in the uncontrollable and mostly external and stable reasons. Keeping this in mind, teachers might highlight the potential malleability of these attributions. They could contribute to the positive environment in school and classroom environment to promote their vivid and clear ideal L2 self. They can also encourage students to exercise more effort rather than depend on maladaptive attributional indicators by means of vision and attribution retraining embedded with goal setting and strategy training (Höl, 2016; Çağatay \& Erten, 2020). As integrating goals and strategy use could help learners to gear more toward taking action rather than blaming uncontrollable causes and abandoning study or using appropriate strategies. For example, dependence on teacher attribution might derive from the esteemed value of them in eastern cultures; however, in order to bolster their ideal L2 selves, attributions on such reasons could be fostered as a belief in the teacher for their account of performance that might lead them to refrain from taking action instead of devoting their time and energy to focus on their effort. With regard to ability, it was found to differ from the other attributions varying across the ideal L2 self. Teachers could pinpoint that the nature of ability is not a stable, fixed or endowed asset but more of a continuum or a potential that can be altered (Özköse-Biylk, 2010). Teachers or program developers could diagnose students with low ideal L2 self and their maladaptive attributions to design effective vision and attribution retraining (Çă̆atay \& Erten, 2020). 
With regard to the predictive power of effort, luck and ability, it can be stated that the theoretical framework of Weiner (1985) has been proved in the study in the sense that causal attributions for past experiences shape future achievements. This finding also consolidates the aforementioned implication that attribution to effort leads learners to believe that their endeavor, or lack thereof, accounts for any future success, so they could contend that they can change their own prospective performance by endorsing effort and striving for success more through their actions. Considering the complexity of the language learning process and motivation, directing motivational orientations strategically and turning them into tools to take proactive steps in students own learning would be the best course of action learners or teachers could take through attribution retraining (Çağatay \& Erten, 2020; Perry et al., 2009) and vision training (Chan, 2014; Magid, 2011).

\section{Acknowledgements}

I owe many thanks and gratitude to the late Prof. Dr. İsmail Hakkı ERTEN from the point we started from scratch for this long study, which actually took three years. Not only did I learn from him on the content and knowledge related to the study, I was also inspired by his ethical mind and his wonderful personality as a prominent researcher and academic in the language teaching field. I wish he could have seen the fruits of the labors of this long-term study we built up together and may he rest in peace.

This article is based on the unpublished dissertation "The Effectiveness of Attribution Retraining on Language Learners' Attributions, Future Self-Guides and Motivated Behaviour, Effort”, submitted to Hacettepe University, Turkey by Dr. Sibel ÇAĞATAY in July, 2018.

\section{The Research and Publication Ethics Statement}

The Ethics Committee/Board approval for this study was obtained from Hacettepe University Ethics Committee, Ankara/ Turkey on 29/08/2016 by No 35853172/4332684. No ethical considerations were violated in this study.

\section{The Conflict of Interest Statement}

In line with the statement of Committee on Publication Ethics (COPE), we hereby declare that we had no conflicting interests regarding any parties of this study.

\section{References}

Al-Shehri, A. S. (2009). Motivation and vision: The relation between the ideal L2 self, imagination and visual style. In Z.Dörnyei \& E. Ushioda (Eds.), Motivation, language identity and the L2 self (pp.164-171). Bristol: Multilingual Matters.

Ayaz- Demir, A. (2016). A study into the relationship between EFL learners' future L2 self guides and L2 achievement. (Unpublished master's Thesis), Hacettepe University, Turkey.

Brady, I. K. (2019). A multidimensional view of L2 motivation in southeast Spain: Through the 'ideal selves' looking glass. Porta Linguarum: revista internacional de didáctica de las lenguas extranjeras, (31), 37-52. 
Chan, H. Y. L. (2014). Possible selves, vision, and dynamic systems theory in second language learning and teaching (Unpublished doctoral dissertation). University of Nottingham, Nottingham UK.

Csizér, K., \& Dörnyei, Z. (2005). Language learners' motivational profiles and their motivated learning behaviour. Language Learning, 55(4), 613-659.

Çağatay, S. \& Erten, İ. H. (2020). The relationship between ideal L2 self, achievement attributions and L2 achievement. In Genç, Z. S. \& Kaçar, I. G. (Eds.), Tesol in the 21st century: Challenges and opportunities (pp. 542- 592). Berlin: Peterlang Publishing.

Dong, Y., Stupnisky, R. H., \& Berry, J. C. (2013). Multiple causal attributions: An investigation of college students learning a foreign language. European Journal of Psychology of Education, 28(4), 1587-1602.

Dörnyei, Z. (2005). The psychology of the language learner: Individual differences in second language acquisition. Mahwah, NJ: Lawrence Erlbaum.

Dörnyei, Z. (2009). The L2 Motivational Self System. In Z.Dörnyei \& E: Ushioda (Eds), Motivation, Language Identity and the L2 self. (pp.120-143). Clevedon: Multilingual Matters.

Dörnyei, Z., \& Chan, L. (2013). Motivation and vision: An analysis of future L2 self images, sensory styles, and imagery capacity across two target languages. Language Learning, 63(3), 437-462.

Dörnyei, Z., \& Ushioda, E. (2011). Teaching and researching: Motivation. Edinburgh Gate: Pearson.

Dörnyei, Z., Henry, A., \& MacIntyre, P. D. (Eds.). (2015). Motivational dynamics in language learning, Bristol, UK: Multilingual Matters.

Dörnyei, Z. (2019). Towards a better understanding of the L2 Learning Experience, the Cinderella of the L2 Motivational Self System. Studies in Second Language Learning and Teaching, 9(1), 19-30.

Dweck, C. (2006). Mindset: The new psychology of success. New York, NY: Random House.

Elliot, A. J. (2005). A conceptual history of the achievement goal construct. Handbook of competence and motivation, 16(2005), 52-72.

Erkorkmaz, Ü., Etikan, İ., Demir, O., Özdamar, K., \& Sanisoğlu, S. Y. (2013). Doğrulayıcı faktör analizi ve uyum indeksleri. Turkiye Klinikleri Journal of Medical Sciences, 33(1), 210-223.

Erler, L., \& Macaro, E. (2011). Decoding ability in French as a foreign language learning motivation. Modern Language Journal, 95(4), 496-518.

Erten, İ. H., \& Burden, R. L. (2014). The relationship between academic self-concept, attributions, and L2 achievement. System, 42, 391-401.

Erten, İ. H. (2015). Age related gender differences in causal attributions of Turkish learners of English as a foreign language. International Association of Research in Foreign Language Education and Applied Linguistics ELT Research Journal, 4(2), 129-146.

Erten, İ. H., Cağatay, S. (2020). Construct Validity of Language Achievement Causal Attribution Scale (LACAS). The Journal of Language Teaching and Learning, 10(1), 19-37.

Faber, G. (2017). The mediating role of foreign language self-concept: Predicting preadolescent EFL learners' causal attributions of grammar success and failure. In J.A. Sorensen \&N.S. Schultz (Eds.), Self-Perception. Research advances and clinical challenges (pp. 1-82). New York (NY): Nova Science Publishers.

Gobel, P., \& Mori, S. (2007). Success and failure in the EFL classroom: Exploring students' attributional beliefs in language learning. EUROSLA yearbook, 7(1), 149-169.

Graham, S. (2004). Giving up on modern foreign languages? Students' perceptions of learning French. The Modern Language Journal, 88(2), 171-191. 
Groves, E.A. (2014). Perceived academic control in community college students: the effect of an online attribution retraining intervention (Unpublished doctoral dissertation). Azusa Pacific University, CA, USA.

Hashemi, M. R., \& Zabihi, R. (2011). Learners' attributional beliefs in success or failure and their performance on the interchange objective placement test. Theory and Practice in Language Studies, 1(8), 954-960.

Haynes, T.L., Perry, R.P., Stupnisky, R.H., \& Daniels, L.M. (2009). A Review of Attributional Retraining treatments: Fostering engagement and persistence in vulnerable college students, in J. Smart (Ed.), Higher Education: Handbook of theory and research, 24, 229-275, The Netherlands: Springer Publishers.

Horwitz, E. K. (1999). Cultural and situational influences on foreign language learners' beliefs about language learning: A review of BALLI studies. System, 27(4), 557-576.

Höl, D. (2016). Exploring locus of control orientations of Turkish EFL learners and the relationship between attributional retraining and academic achievement: an application of an educational training programme (Unpublished doctoral dissertation). Çanakkale Onsekiz Mart University, Turkey.

Hsieh, P. H. P., \& Schallert, D. L. (2008). Implications from self-efficacy and attribution theories for an understanding of undergraduates' motivation in a foreign language course. Contemporary Educational Psychology, 33(4), 513-532.

Hsieh, P. P. H., \& Kang, H. S. (2010). Attribution and self-efficacy and their interrelationship in the Korean EFL context. Language Learning, 60(3), 606-627.

Hu, L. T., \& Bentler, P. M. (1999). Cutoff criteria for fit indexes in covariance structure analysis: Conventional criteria versus new alternatives. Structural equation modeling: $A$ multidisciplinary journal, 6(1), 1-55.

Kalaja, P., Barcelos, A. M. F., \& Aro, M. (2018). Revisiting Research on L2 Learner Beliefs: Looking Back and Looking Forward. In P. Garrett, \& J. M. Cots (Eds.), The Routledge Handbook of Language Awareness (pp. 222-237). New York: Routledge.

Koçyiğit, M. (2011). EFL instructors' causal attributions of student success and failure and their relationship to classroom practices. (Unpublished master's thesis). Afyon Kocatepe University, Turkey.

Kim, T. Y. (2009). Korean elementary school students' perceptual learning style, ideal L2 self, and motivated behavior. Korean Journal of English Language and Linguistics, 9(3), 261-286.

Kim, T. Y., \& Kim, Y. K. (2014). A structural model for perceptual learning styles, the ideal L2 self, motivated behavior, and English proficiency. System,46, 14-27.

Kline, R.B. (2011). Principles and practice of structural equation modeling (3rd ed.). NY: The Guillford Press.

Lei, L., \& Qin, X. (2009). An empirical study of success and failure attributions of EFL learners at the tertiary level in China. Asian EFL Journal, 11(3), 29-51.

Lim, H. (2007). Effects of attributions and task values on foreign language use anxiety. Journal of Educational and Human Development, 1(2), 1-20.

Magid, M. (2011). A validation and application of the L2 motivational self system among Chinese learners of English (Unpublished doctoral dissertation). University of Nottingham, Nottingham, UK.

McClure, J., Meyer, L. H., Garisch, J., Fischer, R., Weir, K. F., \& Walkey, F. H. (2011). Students' attributions for their best and worst marks: Do they relate to achievement?. Contemporary Educational Psychology, 36(2), 71-81.

Mercer, S. (2011). Language learner self-concept: Complexity, continuity and change. System, 39(3), 335-346. 
Mori, S., Thang, S. M., Nor, N. F. M., Suppiah, V. L., \& Oon, S. I. (2011). Attribution tendency and its relationship with actual and perceived proficiency. GEMA: Online Journal of Language Studies, 11(3), 199-218.

Munezane, Y. (2015) Enhancing willingness to communicate: Relative effects of visualization and goal setting, The Modern Language Journal, 99 (1), 175-191.

Oxford, R. L. (2017). 'The craft so long to lerne': Aspects of time in language learning. Innovation in Language Learning and Teaching, 11(3), 282-297.

Öz, H. (2015). Ideal L2 self as a predictor of intercultural communicative competence. Anthropologist, 19(1), 41-53.

Özkardeş, E. (2011). Achievement attributions of preparatory class learners at the school of foreign languages at Pamukkale University for their success or failure in learning English (Unpublished master's thesis). Pamukkale University, Turkey.

Özköse-Blyık, C. (2010). Exploring adult EFL learners' language learning potential: A sociocultural approach. (Unpublished doctoral thesis). State University of New York, Albany, USA.

Paker, T., \& Özkardeş-Döğüş, A. (2017). Achievement attributions of preparatory class learners in learning English. Journal of Language and Linguistic Studies, 13(2), 109135.

Pallant, J. (2011). SPSS survival guide. New York: USA: Open University Press.

Papi, M. (2010). The L2 motivational self system, L2 anxiety, and motivated behavior: A structural equation modeling approach. System, 38(3), 467-479.

Perry, R. P., Stupnisky, R. H., Hall, N. C., Chipperfield, J. G., \& Weiner, B. (2010). Bad starts and better finishes: Attributional retraining and initial performance in competitive achievement settings. Journal of Social and Clinical Psychology, 29(6), 668-700.

Pishghadam, R., \& Zabihi, R. (2011). Foreign language attributions and achievement in foreign language classes. International Journal of Linguistics, 3(1), 1-11.

Roshandel, J., Ghonsooly, B., \& Ghanizadeh, A. (2018). L2 motivational self-system and selfefficacy: a quantitative survey-based study. International Journal of Instruction, 11(1), 329344.

Satıcılar, U. (2006). An investigation into the achievement attributions of English language learners in different grades (Unpublished master's thesis), Çanakkale Onsekiz Mart University, Turkey.

Seligman, M. E. P. (1975). Helplessness: On depression, development, and death. San Francisco, CA: Freeman

Şahinkarakaş, S. (2011). Young students' success and failure attributions in language learning. Social Behavior and Personality: An International Journal, 39(7), 879-885.

Tabachnick, B. G., \& Fidell, L. S. (2013). Using multivariate statistics (6th ed.). Boston, MA: Pearson.

Taguchi, T., Magid, M., \& Papi, M. (2009). The L2 motivational self system among Japanese, Chinese and Iranian learners of English: A comparative study. In Z.Dörnyei \& E. Ushioda (Eds.), Motivation, language identity and the L2 self (pp. 66-97). Bristol: Multilingual Matters.

Taşkıran, A. (2010). Exploring EFL students' causal attributions of perceived success and failure in language learning process. (Unpublished master's thesis), Anadolu University, Turkey.

Taşkıran, A. \& Aydın, B. (2017). EFL learners' causal attributions and dimensionality styles for perceived success and failure. Anadolu University Journal of Social Sciences, 17 (2).1126. 
Teimouri, Y. (2017). L2 selves, emotions, and motivated behaviors. Studies in Second Language Acquisition, 39(4), 681-709.

Ushioda, E. \& Dörnyei, Z. (2009). The L2 Motivational Self System. In Z.Dörnyei \& E: Ushioda (Eds), Motivation, Language Identity and the L2 self (pp.1-8). Clevedon: Multilingual Matters.

Vispoel, W., \& Austin, J. (1995). Success and failure in junior high school: A critical incident approach to understanding students' attributional beliefs. American Educational Research Journal, 32(2), 377-412.

Weiner, B. (1972a). Attribution theory, achievement motivation, and the educational process. Review of Educational Research, 42(2), 203-215.

Weiner, B. (1972b). Theories of motivation: From mechanism to cognition. Chicago: Rand McNally.

Weiner, B. (1985). An attributional theory of achievement motivation and emotion. Psychological Review, 92(4), 548-573.

Weiner, B. (1986). An attributional theory of motivational and emotion. New York: SpringerVerlag Inc.

Weiner, B. (2001). Intrapersonal and interpersonal theories of motivation from an attribution perspective. In Student motivation (pp. 17-30). Springer, Boston, MA.

Weiner, B. (2010). The development of an attribution-based theory of motivation: a history of ideas. Educational Psychologist, 45(1), 28-36.

Weiner, B. (2014). The attribution approach to emotion and motivation: History, hypotheses, home runs, headaches/heartaches. Emotion Review, 6(4), 353-361.

Weiner, B. (2018). The legacy of an attribution approach to motivation and emotion: A no-crisis zone. Motivation Science, 4(1), 4-14.

Williams, M., Burden, R., Poulet, L., \& Maun, I. (2004). Learners' perceptions of their successes and failures in foreign language learning. Language Learning Journal, 30 (1), 1929.

Williams, M., Mercer,S. \& Ryan, S. (2015). Exploring psychology in language learning and teaching. Oxford: Oxford University Press.

Wen, X., \& Piao, M. (2020). Motivational profiles and learning experience across Chinese language proficiency levels. System, 90, 10221.

Zohri, A. (2011). Causal attributions for failure and the effect of gender among Moroccan EFL university learners. English Language Teaching, 4(4), 130-137.

\section{Copyrights}

Copyright for this article is retained by the author(s), with first publication rights granted to the Journal.

This is an open-access article distributed under the terms and conditions of the Creative Commons Attribution license (CC BY-NC-ND) (http://creativecommons.org/licenses/by-nc-nd/4.0/). 